American Journal of Applied Sciences 8 (11): 1154-1158, 2011

ISSN 1546-9239

(C) 2011 Science Publications

\title{
Use of Palm oil Biodiesel Blends as a Fuel for Compression Ignition Engine
}

\author{
${ }^{1}$ B. Deepanraj, ${ }^{1}$ C. Dhanesh, ${ }^{1}$ R. Senthil, ${ }^{1}$ M. Kannan, \\ ${ }^{1}$ A. Santhoshkumar and ${ }^{2} \mathrm{P}$. Lawrence \\ ${ }^{1}$ Department of Mechanical Engineering, \\ Adhiparasakthi Engineering College, Melmaruvathur, India \\ ${ }^{2}$ Department of Mechanical Engineering, \\ Priyadarshini Engineering College, Vaniyambadi, India
}

\begin{abstract}
Problem statement: The increasing awareness of the environmental hazards and the alarming levels of air pollution have led to more restrictive regulations on engines emission control in recent years. Approach: The dwindling resources and rising cost of crude oil had resulted in an intensified search for alternate fuels. In the present study biodiesel (palm oil methyl ester) blends with diesel was investigated in a direct injection stationary diesel engine. The stationary engine test bed used consists of a single-cylinder four stroke diesel engine, eddy current dynamometer with computer control data acquisition system and exhaust emissions analyzer. Results: Engine tests were conducted at constant speed using neat diesel fuel and various proportions of biodiesel blends. The exhaust emissions such as $\mathrm{CO}, \mathrm{HC}$ and $\mathrm{NOx}$ were measured using exhaust gas analyzer. Performance characteristics like brake thermal efficiency and specific fuel consumption were recorded. The differences in the measured emissions and performance of the biodiesel-diesel fuel blends from the baseline operation of the engine, i.e., when working with neat diesel fuel were determined and compared. Conclusion: It is concluded that the lower blends of biodiesel increased the brake thermal efficiency and reduced the fuel consumption. Biodiesel blends produces lower engine emissions than diesel. From the result, it has been established that $20-40 \%$ of palm oil biodiesel can be use as a substitute for diesel without any engine modifications.
\end{abstract}

Key words: Alternate fuel, palm oil, diesel engines, biodiesel, emissions, performance

\section{INTRODUCTION}

Diesel engines are the major source of transportation, power generation, marine applications, etc. Hence diesel is being used extensively, but due to the gradual depletion of fossil fuel reserves and the impact of environmental pollution, there is an urgent need for suitable alternative fuels for the use in CI engine (Kumar et al., 2008). In view of this, Vegetable oils have become more attractive recently because of its environmental benefits and the fact that it is made from renewable resources. Vegetable oils are a renewable and potentially inexhaustible source of energy with an energetic content close to diesel. More than one hundred years ago, Rudolf Diesel tested vegetable oil as the fuel for his engine (Sharma et al., 2008; Anbumani and Singh, 2010). With the advent of cheap petroleum, appropriate crude oil fractions were refined to serve as fuel and diesel fuel and diesel engines evolved together. In the 1930s and 1940s vegetable oils were used as diesel fuel from time to time, but only in emergency situations. Recently, there has been a renewed focus on use of vegetable oils and biodiesel fuel (Suryawanshi, 2006; Prasad et al., 2009). Different kinds of vegetable oils and biodiesel have been tested in diesel engines. Its reducing characteristic for greenhouse gas emissions, its help on reducing a country's reliance on crude oil imports, its supportive characteristic on agriculture by providing a new market for domestic crops, its effective lubricating property that eliminates the need of any lubricate additive and its wide acceptance by vehicle manufacturers can be listed as the most important advantages of the biodiesel fuel (Srivastava and Verma, 2008; Karaosmanoplu, 1999; Lawrence et al., 2011; Singh and Singh, 2010). There are more than 350 oilbearing crops identified, among which only jatropha,

Corresponding Author: B. Deepanraj, Department of Mechanical Engineering, Adhiparasakthi Engineering College, Melmaruvathur-603319, Kancheepuram District, Tamilnadu, India 
ongamia, sunflower, safflower, soyabean, cottonseed, rapeseed and peanut oils are considered as potential alternative fuels for diesel engines. The present study aims to investigate the use of palm oil as an alternate fuel for compression ignition engine.

\section{MATERIALS AND METHODS}

Biodiesel Preparation: Biodiesel is the ester of vegetable oils produced through a process called transesterification. Transesterification is a chemical reaction which occurs between triglyceride and alcohol (generally methyl alcohol) in the presence of a catalyst (generally sodium hydroxide of potassium hydroxide). It consists of a sequence of three consecutive reactions where triglycerides are converted to diglycerides; diglycerides are converted to monoglycerides followed by the conversion of monoglycerides to glycerol (Fukuda et al., 2001; Vivek and Gupta, 2004). In each step an ester is produced and thus three ester molecules are produced from one molecule of triglyceride.

Palm oil used in the present investigation was taken from the local market and filtered by cheesecloth to remove the solid particles. The moisture content was removed by heating the oil in an oven up to $110^{\circ} \mathrm{C}$ for one hour. Now the oil is taken in a round bottom flask of volume $500 \mathrm{~cm} 3$ and heated around $50-60^{\circ} \mathrm{C}$ on a hot plate having magnetic stirrer arrangement. Then methanol and sodium hydroxide (catalyst) are added to the oil. The mixture was stirred continuously. Alcohol to vegetable oil molar ratio is one of the important factors that affect the conversion efficiency of the process. For the transesterification process, $3 \mathrm{~mol}$ of alcohol are required for each mole of the oil. However, in practice, the molar ratio should be higher than this theoretical ratio in order to drive the reaction towards early completion.

After the completion of reaction, the products are allowed to separate into two layers. The lower layer contains glycerol and the top layer contains ester which is separated and purified using distilled water. Hot distilled water ( $10 \%$ by volume) is sprayed over the ester and stirred gently and allowed to settle in the separating funnel. The lower layer is discarded and upper layer (purified biodiesel) is separated (Naik et al., 2006; Anandram et al., 2006).

Biodiesel (methyl esters of palm oil) have several outstanding advantages among other new-renewable and clean engine fuel alternatives. The properties of diesel and biodiesel (palm oil methyl ester) used in the present investigation were compared with diesel fuel in Table 1.
Table 1: Properties of diesel and biodiesel

\begin{tabular}{lrr}
\hline Properties & \multicolumn{1}{c}{ Diesel } & Biodiesel \\
\hline Calorific value $\left(\mathrm{kJ} / \mathrm{kg}^{1}\right)$ & 42400.000 & 39070.000 \\
Specific gravity & 0.822 & 0.843 \\
Viscosity at $40^{\circ} \mathrm{C}(\mathrm{c}-\mathrm{s})$ & 3.720 & 7.100 \\
Flash point $\left({ }^{\circ} \mathrm{C}\right)$ & 62.000 & 108.000 \\
Flash point $\left({ }^{\circ} \mathrm{C}\right)$ & 75.000 & 114.000 \\
Iodine value & 38.300 & 71.440 \\
\hline
\end{tabular}

Table 2: Specification of test engine

\begin{tabular}{ll}
\hline Engine type & 4 stroke, single cylinder, DI Engine \\
\hline Stroke & $110 \mathrm{~mm}$ \\
Bore & $80 \mathrm{~mm}$ \\
Power & $3.68 \mathrm{~kW}$ \\
Rated speed & $1500 \mathrm{rpm}$ \\
Cooling type & Water cooled \\
Loading type & Eddy current dynamometer \\
\hline
\end{tabular}

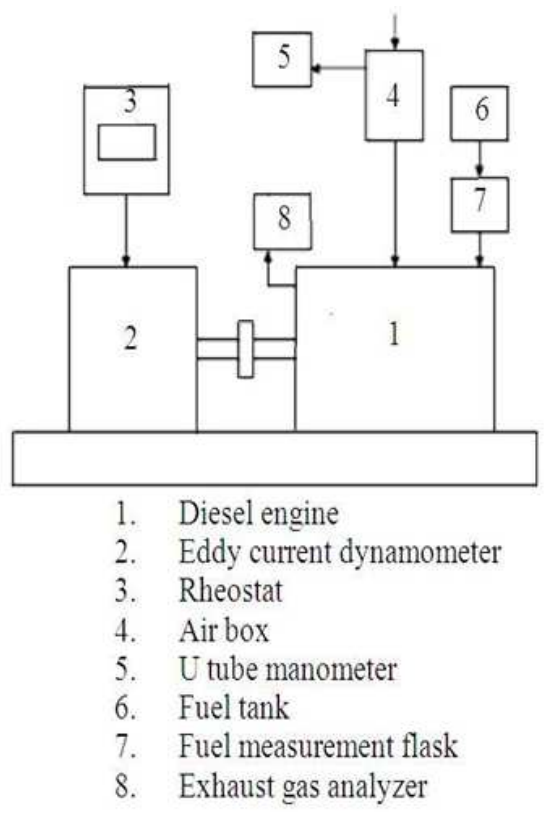

Fig. 1: Experimental setup

Experimental setup and procedure: A four stroke, single cylinder, water cooled, direct injection diesel engine was used for the performance tests. The specification of the test engine is shown in Table 2. The experimental set-up diagram is shown in Fig. 1. Experiments were carried out initially using neat diesel fuel to generate the base line data. After recording the base line data, tests were carried out using 10, 20, 30, 40 and $50 \%$ biodiesel blends. The engine tests were conducted at various loads starting from no load to full load and the parameters related to performance and emission characteristics were recorded. 


\section{RESULTS AND DISCUSSION}

The emission and performance characteristics of the engine are presented for different percentages of load for diesel and biodiesel blends.

Figure 2 shows the variation of unburned hydrocarbon (HC) emission with respect to load. The unburned hydrocarbon emission gradually increases with increase in load. This is due to the increased amount of fuel injection at higher loads. At maximum load condition B30, B40 and B50 blends produce 17.54, 19.4 and $21.3 \%$ lower $\mathrm{HC}$ emission respectively than neat diesel fuel. This is due to the complete and stable combustion of the biodiesel, which contains more number of oxygen atoms.

Figure 3 shows the variation of carbon monoxide (CO) emission with respect to different loads. The CO emission increases with increase in load. From the figure it is observed that the biodiesel blends produce lower $\mathrm{CO}$ emission than diesel. At $50 \%$ load condition, B30 and B40 produce 36.5 and $41.23 \%$ less CO emission than diesel. This is due to the complete and stable combustion of the biodiesel, which contains more number of oxygen atoms.

Figure 4 shows the variation of NOx emission with respect to load. From the figure, it was observed that biodiesel blends produces higher NOx emission than diesel fuel at both full and partial loads. At maximum load, B40 and B50 blend produce 19.6 and 22.13\% higher NOx emission than neat diesel fuel. For 50\% load condition, these blends produce 18.46 and $29.05 \%$ higher NOx emission than diesel fuel. This is because of higher temperature of combustion and the presence of fuel oxygen with the biodiesel blends.

Figure 5 shows the variation of brake thermal efficiency with different loads for different biodiesel blends and diesel. The brake thermal efficiency is defined as the actual brake work per cycle divided by the amount of fuel chemical energy. From the figure it is observed that brake thermal efficiency increases with increase of load. At maximum load, B40 and B50 blends produce 8.95 and $12.85 \%$ lower brake thermal efficiency than diesel. This reduction in brake thermal efficiency with biodiesel blends was due to higher viscosity, poor spray characteristics and lower calorific value. The higher viscosity leads to decreased atomization, fuel vaporization and combustion and hence the thermal efficiency of the biodiesel blends is lower than that of diesel.
Specific Fuel Consumption (SFC) is a measure of the efficiency of the engine in using the fuel supplied to produce work. It is desirable to obtain a lower value of SFC meaning that the engine used less fuel to produce the same amount of work. Figure 6 shows the SFC of POME blends with diesel. The specific fuel consumption keeps on decreasing with increasing load. It can be seen from the figure that in case of biodiesel blends, the specific fuel consumption values were determined to be higher than that of neat diesel fuel. At maximum load condition, B40 and B50 blends produce 7.9 and $13.04 \%$ higher SFC than neat diesel fuel. This trend was observed owing to the fact that biodiesel blends have lower calorific value than neat diesel fuel and thus more amount of biodiesel blend was required for the maintenance of a constant power output.

Figure 7 shows the variation of exhaust gas temperature with different loads for different biodiesel blends and diesel. The results show that the exhaust gas temperature increased with increase in load in all cases.

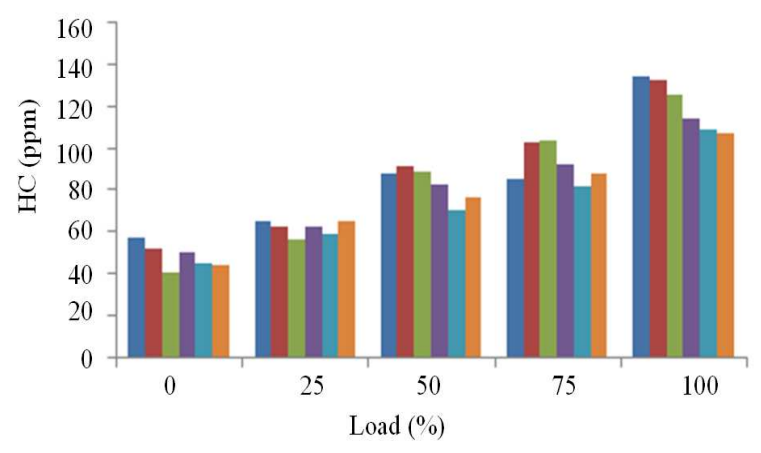

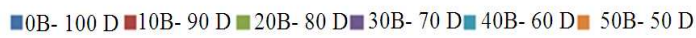

Fig. 2: HC Vs load

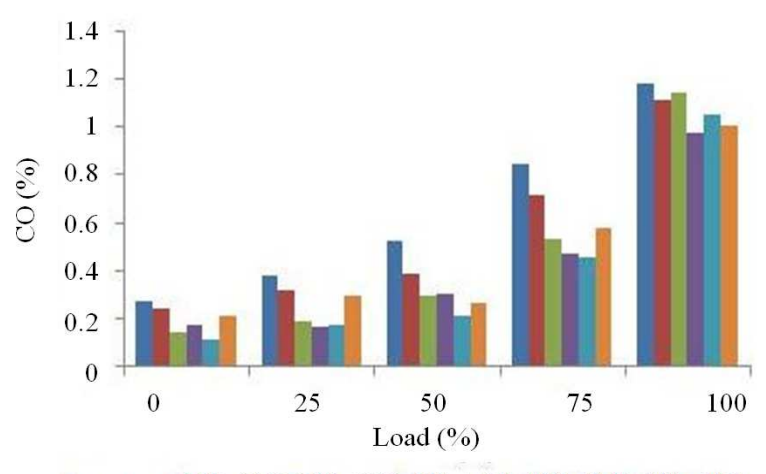

= $0 \mathrm{~B}-100 \mathrm{D} \backsim 0 \mathrm{~B}-90 \mathrm{D}=20 \mathrm{~B}-80 \mathrm{D} \backsim 30 \mathrm{~B}-70 \mathrm{D}=40 \mathrm{~B}-60 \mathrm{D}=50 \mathrm{~B}-50 \mathrm{D}$

Fig. 3: CO Vs load 


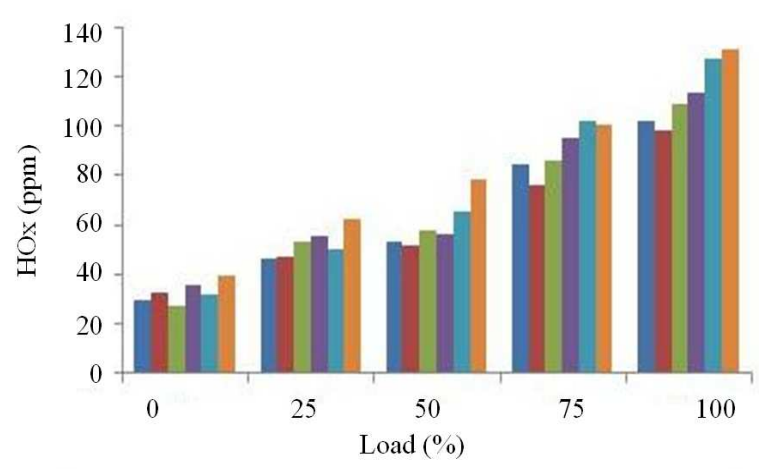

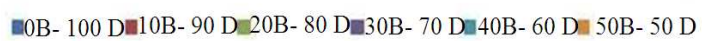

Fig. 4: NOx Vs load

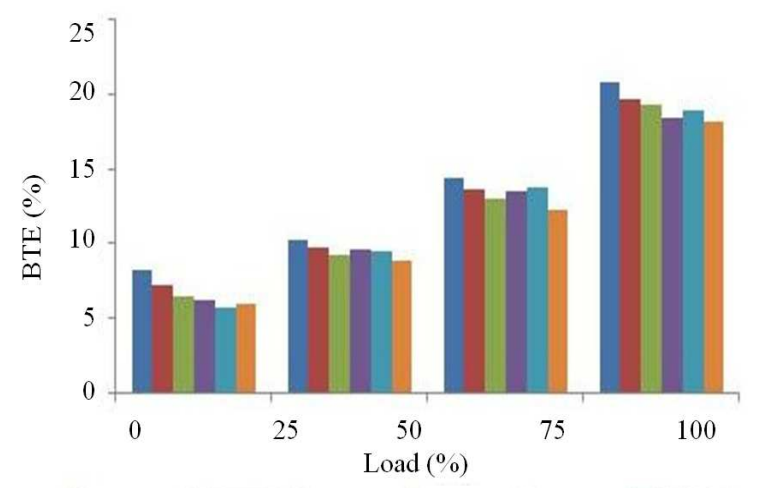

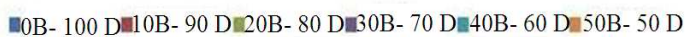

Fig. 5: BTE Vs. Load

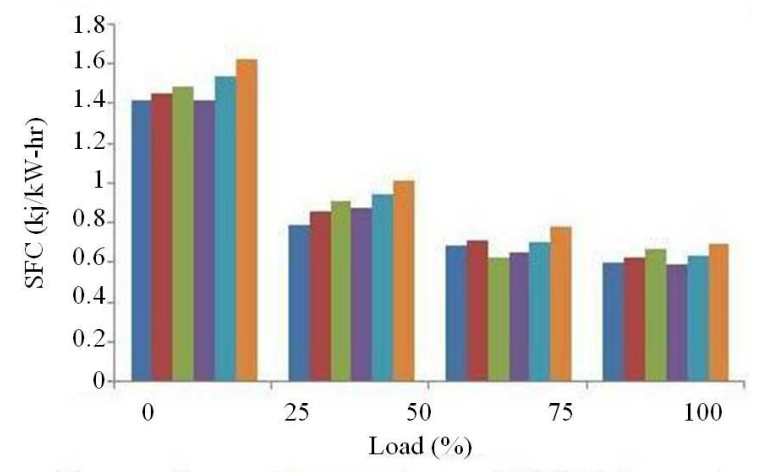

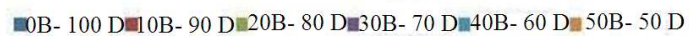

Fig. 6: SFC Vs load

At maximum load condition, B50 produces highest EGT which is $28.05 \%$ higher than that of diesel. This could be due to higher quantity of fuel being consumed per hour for biodiesel blends compared to that of diesel in each load setting of the engine.

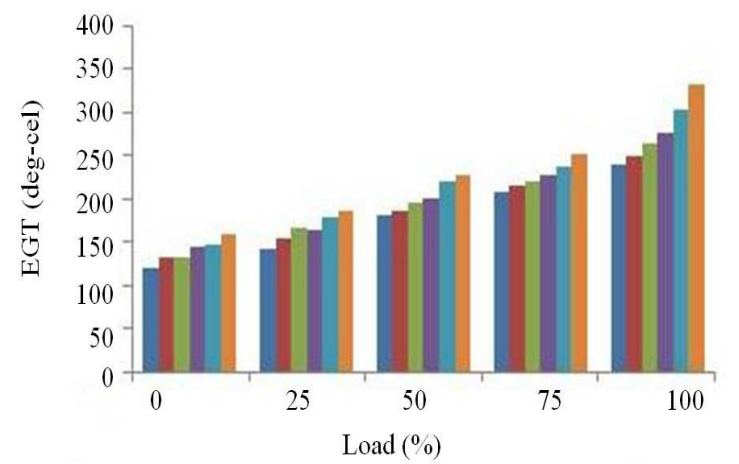

$\approx 0 \mathrm{~B}-100 \mathrm{D}=10 \mathrm{~B}-90 \mathrm{D}=20 \mathrm{~B}-80 \mathrm{D}=30 \mathrm{~B}-70 \mathrm{D}=40 \mathrm{~B}-60 \mathrm{D}=50 \mathrm{~B}-50 \mathrm{D}$

Fig. 7: EGT Vs load

\section{CONCLUSION}

From the experimental analysis it was found that the blends of POME and diesel could be successfully used with acceptable performance and better emissions up to a certain extent. The result of this analysis was summarized as follows:

- The biodiesel blends produce lower carbon monoxide and unburned hydrocarbon emission than neat diesel fuel due to the availability of oxygen content

- Biodiesel produces higher oxides of nitrogen than diesel because of the higher temperature inside the combustion chamber

- Biodiesel blends produce lower brake thermal efficiency and higher specific fuel consumption than diesel because of the low calorific value

- Biodiesel blends produce higher exhaust gas temperature than neat diesel fuel

\section{REFERENCES}

Anandram, V., S. Ramakrishnan, J. Karthik, S. Saravanan and G.L.N. Rao, 2006. Engine analysis of single cylinder di diesel engine fuelled with sunflower oil, sunflower oil methyl ester and its blends. Proceedings of the ASME Internal Combustion Engine Division 2006 Fall Technical Conference, Nov. 5-8, Sacramento, California, USA, pp: 219-224. DOI: 10.1115/ICEF2006-1573

Anbumani, K. and A.P. Singh, 2010. Performance of mustard and neem oil blends with diesel fuel in C.I. engine. ARPN J. Eng. Applied Sci., 5: 14-20.

Fukuda, H., A. Kondo and H. Noda 2001. Biodiesel fuel production by transesterification of oils. J. Biosci. Bioeng., 92: 405-416. DOI: 10.1016/S1389-1723(01)80288-7 
Karaosmanoplu, F., 1999. Vegetable oil fuels: A review. Ene. Sour., 21: 221-231.

Lawrence, P., K. Mathews and B. Deepanraj, 2011. The effect of prickly poppy methyl ester blends on CI engine performance and emission characteristics. Am. J. Environ. Sci., 7: 145-149. DOI: 10.3844/ajessp.2011.145.149

Singh, P., J. Khurma and A. Singh, 2010. Coconut oil based hybrid fuels as alternative fuel for diesel engines. Am. J. Environ. Sci., 6: 71-77. DOI: 10.3844/ajessp.2010.71.77

Kumar, P.R., K. Rajagopal, R.H. Prakash and B.D. Prasad, 2008. Performance of CI engine using blends of methyl esters of palm oil with diesel. J. Eng. Applied Sci., 3: 217-220. DOI: 10.3923/jeasci.2008.217.220
Sharma, Y.C., B. Singh and S.N. Upadhyay, 2008. Advancements in development and characterization of biodiesel: A review. Fuel, 87: 2355-2373. DOI: 10.1016/j.fuel.2008.01.014

Srivastava, P.K. and M. Verma, 2008. Methyl ester of karanja oil as an alternative renewable source energy. Fuel., 87: 1673-1677. DOI: 10.1016/j.fuel.2007.08.018

Suryawanshi, J., 2006. Performance and emission characteristics of $\mathrm{CI}$ engine fueled by coconut oil methyl ester. Visvesvaraya National Institute of Technology.

Vivek and A.K. Gupta, 2004. Biodiesel production from karanja oil. J Sci. Indu. Res., 63: 39-47. 